\title{
Reproductive outcomes in women prenatally exposed to undernutrition: a review of findings from the Dutch famine birth cohort
}

\author{
L. H. Lumey \\ American Health Foundation, 320 East 43rd Street, New York, NY 10017 and Columbia University College of Physicians and \\ Surgeons, New York, NY 10032, USA and Academic Medical Center, 1105 AZ Amsterdam, The Netherlands
}

Recent studies suggest that the effects of the amount and quality of intra-uterine nutrition may extend to adult life. Work in this area has focused on the association between birth weight (as a proxy for fetal nutrition) and the onset of adult chronic conditions in normal populations (Barker, 1992, 1994). The circumstances of the Dutch famine provide an opportunity to examine the relationships between intra-uterine nutrition, birth weight, and adult health in considerable detail, and across a range of intrauterine exposure not normally observed in human populations.

In the present review of the findings from the Dutch famine birth cohort study we will show that an acute reduction in intra-uterine nutrition of women can indeed have long-term health effects on them and on their offspring. However, these effects critically depend on the timing of exposure in relation to the stage of pregnancy and are mostly independent of the mother's own birth weight. The fetal origins hypothesis (Barker, 1995) needs to be modified accordingly.

\section{Historical background}

A severe famine affected the western Netherlands in the winter of 1944-5 and occurred in a society with a welldeveloped administrative structure where food supplies had been generally adequate (Burger et al. 1948; De Jong, 1981; Trienekens, 1985). The famine was the result of an embargo on transport of food supplies to the western cities, imposed by the German occupying forces in reprisal for a wave of partisan activity and a nationwide strike of the railway workers.

During the famine, per capita food availability was progressively reduced, from pre-famine levels of approximately $6700 \mathrm{~kJ} / \mathrm{d}$ in September 1944 to under $5400 \mathrm{~kJ} / \mathrm{d}$ by April 1945. Government food rations for the population in the west declined much more rapidly, and were below $4200 \mathrm{~kJ} / \mathrm{d}$ between January and April 1945. The famine ceased immediately with Liberation in May 1945, when Allied food supplies became abundant.
The famine was associated with a dramatic increase in mortality and morbidity (Burger et al. 1948; De Jong, 1981; Lumey \& Van Poppel, 1994) and with a $350 \mathrm{~g}$ decrease in infant birth weight (Smith, 1947; Sindram, 1953; Stein et al. 1975; Stein et al. 1995). Major cities in the famine area included Amsterdam, Rotterdam, and The Hague. The famine did not affect the northern Netherlands where all necessary foods were locally grown or the southern Netherlands which had already been liberated by the Allied forces. Because of the historical circumstances, the famine can be analysed as a natural experiment of the effects of the withholding of food among a population relatively well defined by place and time. In addition, place (famine $v$. non-famine region) and time (famine $v$. non-famine period) of an individual's residence in The Netherlands provide an approximate measure of famine exposure at the individual level.

\section{Materials and methods}

Study cohort

The Dutch famine birth cohort study is a study of selected women born in Amsterdam before, during and after the hunger period. Recruitment details have been published elsewhere (Lumey et al. 1993). We located the obstetric records of all 1116 females born between 1 August 1944 and 15 April 1946 at the Department of Obstetrics and Gynecology, Wilhelmina Gasthuis Hospital, Amsterdam, and collected information about these births from hospital administrative and medical records that provide, among other details, personal identifiers, date of birth and birth weight. The series included 1067 singleton births.

\section{Exposure definitions}

We estimated the degree and timing of an individual's exposure to famine in each trimester of pregnancy, based on records of the government food rations for all monthly cohorts born in Amsterdam between August 1944 and April 1946 (Burger et al. 1948; Stein et al. 1975). For all subjects the date of conception was estimated by assuming that the 
duration of pregnancy was nine calendar months. Since the length of gestation during the famine was reduced by $4 \mathrm{~d}$ on average (Stein et al. 1975) this estimate is sufficiently accurate for our purpose. The calendar month of birth was numbered 10 , the preceding month 9 , and so on to 1 , the month of last menstrual period. Intra-uterine famine exposure was defined separately for trimesters 1,2 , and 3 as an average official ration of less than $4200 \mathrm{~kJ}$ daily in that trimester. The mean ration in the first trimester was the average daily ration in months 1,2 , and 3 ; for the second trimester the ration in months 4,5 , and 6 ; for the third trimester the ration in months 7,8 , and 9 . Using this definition the cohorts severely exposed in utero to famine in the first trimester were born between August and December 1945; cohorts exposed in the second trimester were born between May and September 1945, and cohorts exposed in the third trimester between February and June 1945. All other monthly birth cohorts were defined as unexposed in those trimesters. Subjects born in May and June 1945 were severely exposed in both the second and the third, and subjects born in August and September 1945 were exposed in both the first and the second trimester.

\section{Outcomes}

\section{Outcomes at birth}

There was a sharp decrease in the women's birth weights associated with famine exposure in the third trimester of pregnancy only (Smith, 1947; Sindram, 1953; Stein et al. 1975; Stein et al. 1995). In this group, (maternal) pregnancy weight loss or a weight gain of less than $0.5 \mathrm{~kg} /$ week was strongly associated with a woman's size at birth. At maternal weight gains greater than $0.5 \mathrm{~kg} /$ week, further weight gain was no longer associated with a woman's birth size (Stein et al. 1995). Placental weight was not recorded for the births of the study cohort but was available for selected hospital births in Rotterdam where there was some evidence for compensatory placental growth after famine exposure in the first trimester of pregnancy (Lumey, 1998).

\section{Follow-up}

Long-term follow-up of all women was carried out through the national population registers, introduced in The Netherlands during the occupation by the French under Napoleon. This allowed us to trace and to invite all study subjects who were still alive and resident in The Netherlands to participate in the study. Follow-up status in 1987 (died, emigrated, or currently resident in The Netherlands) was confirmed for all subjects. Of the cohort, $17 \%$ were still-born or had subsequently died, and $8 \%$ had left the country. Home interviews were completed for 700 women, comprising $84 \%$ of the surviving subjects resident in the country,

There were no differences in several selected characteristics recorded in 1944-5 (maternal age, proportion of primiparae, proportion unmarried, proportion with a husband of low occupational level) when comparing the obstetric records of the mothers of the women not interviewed due to death, emigration, or refusal to participate in the study, with the women who were successfully interviewed in 1987-91. Furthermore, there were no differences in either birth size or gestational age between the interviewed women and those who had died, emigrated, or refused to participate in the study (Lumey et al. 1993).

\section{Reproductive outcomes}

Relevant information about a woman's medical and social history was collected in the course of home interviews conducted between 1987 and 1991. For each woman this included self-reported height and weight at age 18 years, education, smoking habits, the place and date of birth, and the sex and birth weight of all her offspring. In addition, we searched for extant hospital and/or well-baby-clinic records to validate the interview data. These were found for $66 \%$ of all births. With these multiple sources of information, we have shown that estimates of offspring birth weight obtained by maternal recall in this population are accurate and unbiased, except among still-born and non-surviving infants (Lumey et al. 1994) and, therefore, we used recalled birth weight in subsequent analyses. All interviews were performed by a single trained research nurse.

Of the women interviewed, $98 \%$ were singletons and $89 \%$ had delivered one or more children. The total number of offspring was 1334 , and for $97 \%$ of these, the women provided an estimated birth weight. The proportions of first-, second-, third-, and fourth- and later-born among the offspring were $47,37,11$ and $4 \%$ respectively.

\section{Fertility}

Among the women who were interviewed, fetal undernutrition was not associated with subsequent fertility, including age at first pregnancy, completed family size, or inter-pregnancy interval.. In addition, none of these outcomes was associated with birth weight itself. However, there was an increase in the risk of still-birth and perinatal death among offspring of women prenatally exposed to famine in the third trimester of pregnancy (Lumey \& Stein, 1998).

\section{Offspring birth weights across families}

We observed parity-specific effects of a woman's perinatal nutrition on offspring birth weight. Looking across all families, and ignoring within-family birth-weight patterns, there was an increase in the average birth weight of all firstborn and a reduction in birth weights of all later-born offspring of mothers prenatally exposed in the first trimester of pregnancy (Lumey et al. 1995a,b). Whereas a substantial ( $200 \mathrm{~g}$ or more) impact of a woman's intrauterine exposure on the birth weights of her offspring could be ruled out, this analysis was not powerful enough to exclude parity-specific, moderate $(50-100 \mathrm{~g})$ effects. In addition, confounding by unmeasured maternal determinants of offspring birth weight, of genetic, physical or 
behavioural origin, could have occurred. To exclude such confounding, a within-family analysis of the parity-specific differences of the offspring birth weights was carried out.

\section{Offspring birth weights within families}

Birth weights in second-born infants normally exceed birth weights in first-born infants, and there is little if any increase for additional pregnancies (Billewicz \& Thomson, 1973). In addition, birth weights within sibships are highly correlated (Bakketeig et al. 1979). We undertook an analysis of the within-family birth-weight patterns to see if these patterns differed depending on the timing of a woman's intra-uterine exposure to undernutrition. This was indeed the case, as our analysis showed an abnormal within-sibship decrease in birth weight with increasing birth order among offspring of women exposed in the first trimester of pregnancy. The birth weight decline was over $250 \mathrm{~g}$ comparing second-born with first-born, and over $350 \mathrm{~g}$ when comparing third-born with first-born offspring (Lumey \& Stein, 1997). Adjustment for potential confounders, including maternal body size, did not affect this relationship. The normal increase in birth weights with increasing birth order was seen among the offspring of women exposed in mid and later pregnancy and in women without intra-uterine exposure. This within-family analysis confirms and extends our previous across-family analyses (Lumey et al. 1995a,b).

\section{Mother-child birth weight correlations}

There was a strong association between the mothers' birth weights and those of their first-born offspring, regardless of the mothers' own intra-uterine nutrition (Stein \& Lumey, 1996). The association was linear for maternal birth weights of above approximately $2500 \mathrm{~g}$. The patterns in later-born offspring have not yet been examined.

\section{Other outcomes}

Adult weight among the interviewed women was increased after prenatal first-trimester exposure and unaffected after prenatal third-trimester exposure. These findings apply both to recalled prepregnancy weight and to weight at the time of the home interview (Ravelli et al. 1992). For a subset of women, adult blood pressure is available from obstetric records at the beginning of their first and second pregnancy when they were on average 21 and 25 years old. There was no relationship between systolic and diastolic pregnancy blood pressure $(\mathrm{mmHg}$ ) and a woman's famine exposure status or with her own birth weight (Lumey, unpublished results). We are currently examining the relationship between famine exposure, adult body size, and blood pressure in more detail.

\section{Discussion}

\section{Summary of findings}

The normal increase in offspring birth weights with increasing birth order as documented by various crosssectional (Thomson et al. 1968; Kloosterman, 1970) and longitudinal (Karn et al. 1951; Billewicz \& Thomson, 1973) studies was not seen among women after intrauterine exposure to undernutrition in the first trimester of pregnancy. Instead, this pattern was reversed and we saw a within-sibship birth weight decrease with increasing birth order among offspring of these women. These effects were not associated with maternal body size.

A decreased efficiency of a woman's uterine circulation with successive pregnancies would provide an explanation for the effect but the biological mechanism remains elusive. There were no differences in maternal pregnancy blood pressure or in the clinical prevalence of pre-eclampsia among these mothers, but the number of (pre)eclamptic women in the study was small. Other relevant variables regarding the quality of the materno-fetal circulation were not collected.

Our within-sibship analysis of the offspring birth weights was based on the belief that sibships are characterized by birth weights which, to a large extent, are determined by maternal characteristics. From that perspective, the comparison of paired birth-weight differences within families is a logical approach, because it naturally controls for differences in several genetic, social and behavioural attributes which are hard to measure, and present a source of confounding which is not easily controlled. Many of these attributes differ between women, but remain constant over time for each, such as family-related behaviours, socio-economic status or education. For some changing physical characteristics such as maternal height and weight our approach provides an effective adjustment for baseline values.

A significant relationship between famine exposure during early gestation and increased adult (height-adjusted) weight was also seen in this cohort. This relationship had already been described in famine-born males in The Netherlands (Ravelli et al. 1976). The weight increase may be due to a change in metabolic efficiency in these subjects, to an increase in nutritional intake, or to lower levels of physical activity. It is also possible that diet and the prenatal or early postnatal environment interact to produce changes in the fetal brain that may have permanent effects, possibly through changes in appetite and weight control throughout life. This needs to be explored in more detail. As mentioned earlier, the birth weight outcomes in the offspring are independent of changes in a woman's adult size.

In view of the historical circumstances, no distinction can be made between the effects of intra-uterine undernutrition during early gestation and the effects of postnatal rehabilitation during mid and late gestation. These exposures are inextricably linked in the study population. Our present understanding suggests, however, that undernutrition should be the exposure of primary interest.

\section{Potential for biased outcomes}

Follow-up of this cohort was virtually complete after 45 years, and there were no differences in the birth characteristics of the women with completed (about $85 \%$ ) and not completed home interviews. All cohort members 
still living in The Netherlands were contacted for an interview, regardless of their current place of residence, and the between-family and within-family analyses gave essentially the same results. For the previously stated reasons, concerns relating to the possibility of confounding for lack of control of socio-economic status, the potential for selection bias due to incomplete follow-up, or the potential for bias related to migration (Paneth \& Susser, 1995; Jones \& Swerdlow, 1996; Kramer \& Joseph, 1996) are not likely to apply to this cohort.

\section{Other famine studies}

Before starting the Dutch famine birth cohort study, we had assembled an incomplete birth cohort of women, first ascertained not at birth, but at delivery of their first child in the Amsterdam teaching hospital between 1960 and 1984. In this incomplete cohort, we reported a birth weight decrease among first-born offspring of Amsterdam-born women after prenatal exposure early in pregnancy between July and September 1945 (Lumey, 1988, 1992). Following the suggestion of Stein et al. (1975), offspring birth weights in the incomplete cohort had been tabulated for eight maternal birth cohorts, according to the likely exposure of their mothers during gestation and early postnatal life, to test for the presence of critical periods with adequate numbers. Because of the sampling design, women who delivered their infants elsewhere could not be identified and neither could women without offspring. Based on our findings at the time, the following study hypothesis was formulated in 1989 to guide further research:

'In utero exposure to famine of the female fetus, even if followed by adequate postnatal and childhood diet and full adult stature, is associated with low birth weight and intrauterine growth retardation in her offspring. The effects may relate to early pregnancy fetal exposure of the woman, and not necessarily to her birth weight, which in this natural experiment was related to third-trimester exposure' (Barker, 1992, 1994).

This hypothesis was tested from 1995 onwards in the (complete) Dutch famine birth cohort where the maternal birth cohorts are defined by an average official ration of less than $4200 \mathrm{~kJ}$ daily in each of the three pregnancy trimesters. While the birth weights among second- and later-born offspring in the complete birth cohort are in agreement with our hypothesis, the birth weights of the first-born offspring show an increase. Initially (Lumey et al. 1995a; Lumey, 1996), the discrepancy between the two studies regarding the first-born offspring was attributed to sampling variability or to the difference in study design. However, a re-analysis of the women of the incomplete cohort, with prenatal famine exposure now defined by the level of the official rations, also shows an increase in the birth weights of the first-born infants after maternal early in utero exposure (Lumey, unpublished results). The findings from the two cohorts are therefore consistent in showing a birth-weight increase in first-born offspring. Our original hypothesis needs to be refined accordingly to allow for parity-specific birth weight effects in the offspring.

\section{Other human studies}

With regard to second-generation effects, the birth cohort study did not show any long-term consequences on offspring birth-weight patterns after a woman's intrauterine undernutrition late in gestation (which significantly lowered birth weights in her own generation). These findings are in agreement with other human studies. Magnus et al. (1985) showed that monozygotic female twins discordant ( $>300 \mathrm{~g}$ ) for birth weight have offspring of similar birth weight. Emanuel et al. (1992), studying singleton and twin mothers discordant for birth weight reported similar findings. Therefore, the prenatal timing of a nutritional insult rather than its effect on maternal birth weight itself seems critical for any health effects on the next generation. Specifically, it points towards a predominant role of first-trimester intra-uterine undernutrition (which does not affect a woman's birth weight) as opposed to third-trimester intra-uterine undernutrition (after which a woman's birth weight may be severely depressed) for longterm health outcomes. These relationships confirm that 'the effects of pre-natal nutrition are obscured if the nutritional exposure is not closely defined in terms of the developmental timing (as well as duration, severity and type)' (Susser \& Stein, 1994) and also speak against a direct relationship between a woman's birth weight and her reproductive outcomes in adulthood.

\section{Animal studies}

There is considerable evidence from animal studies that changes in nutrition in early life can permanently affect the growth and form of the body, its structures and functions (McCance \& Widdowson, 1974). As an example of firstgeneration effects, guinea-pigs experimentally undernourished in utero by reducing the food supplies of the mothers were born small and became smaller adults than the young of well-fed mothers (Lister \& McCance, 1965). A congenital deficiency in uterine blood supply had similar effects (Widdowson, 1971). In many instances, such longterm effects are associated with undernutrition early in pregnancy, because of the increased sensitivity of the cell to undernutrition in periods of cell division compared with periods of cell growth (Winick \& Noble, 1965, 1966).

In rat studies, a decrease in offspring birth weights was seen after multi-generational chronic maternal undernutrition throughout pregnancy and after birth (Stewart et al. 1975; Zamenhof \& Van Martens, 1982). A distinction between the effects of early $v$. late pregnancy insults could not be made in these studies because of the exposure throughout pregnancy.

\section{Nutrition in pregnancy, birth weight, and adult health}

With regard to the use of birth weight as a proxy measure of fetal nutrition, several observations can be made. It may be intuitively appealing to assume that there should be a considerable positive association between a woman's nutrition and the size of her newborn. Unfortunately, this is not borne out by a review of the findings of several well- 
designed nutrition studies (Lumey, 1993). First, most of the variance in birth weight cannot be explained by established risk factors of any kind. This can be seen in the data from the Collaborative Perinatal Project in the United States (1959-1965), in which the combination of thirty risk factors could only explain one-third of the variance in birth weight (Weiss \& Jackson, 1969). The risk factors explaining the most variance were maternal weight gain in pregnancy (6\% explained), prepregnancy weight (5\%), birth weight of the previous infant $(5 \%)$, and maternal smoking in pregnancy (3\%). While the two measures of maternal body size seem the most associated with birth weight, it is not at all clear that these factors reflect maternal nutrition during the pregnancy of interest.

Moreover, a review of the Dutch famine data on nutritional deprivation and of several randomized clinical studies of nutritional supplementation in pregnancy shows that birth weight is relatively insensitive to changes in maternal diet (Lumey, 1993). In the Dutch famine studies we see no effect on birth weight after undernutrition in the first or second trimester of pregnancy. Even the $350 \mathrm{~g}$ birth weight decrease seen after undernutrition in the third trimester is relatively small (less than $0.5 \mathrm{SD}$ ) compared with the variance of birth weight in the population. The analysis of several trials of nutritional supplementation in pregnancy (New York City, Bogota, Guatemala, Taiwan) suggest that the increase in infant birth weight that can be achieved is even smaller (50-100 g). Because the relationship between maternal nutrition and infant birth weight is not very specific at best, and critically depends on the timing in relation to pregnancy trimester, studies of the long-term effects of postulated changes in pregnancy nutrition should not use infant birth weight (or any other measure of size at birth) as a measure of the quality or quantity of a woman's diet in pregnancy. With regard to the fetal origins hypothesis (Barker, 1995) the following modification would be consistent with our findings: 'longterm health effects after fetal undernutrition may occur in the absence of a birth weight effect, and may not be apparent even in its presence'.

In this context we need to comment on Professor Barker's representation of the effects of fetal undernutrition according to trimester of pregnancy, as it provides, in his words, 'a framework within which the links between fetal undernutrition and cardiovascular disease can be explored' (Barker, 1994). In his proposed scheme, undernutrition in early gestation leads to a baby who is small at birth, which may predispose to hypertension and haemorrhagic stroke but not to CHD. By contrast, undernutrition in late gestation leads to a baby with a normal birth weight who as an adult has raised blood cholesterol and fibrinogen concentrations, and is predisposed to CHD and stroke. In the light of the evidence from the Dutch famine and other war-induced famine studies in Russia and Germany (cited by Barker, 1994), all of which show a dramatic decline in birth weight after malnutrition during the second half of gestation and no decline in birth weight after malnutrition during the first half of gestation, the postulated schematic effects of fetal undernutrition according to trimester of pregnancy on birth weight are at odds with all available data and need to be modified accordingly.

\section{Suggestion for future studies}

Because of the difficulties in interpreting a fetal origins hypothesis (Barker, 1992, 1994) which postulates associations between size at birth (as a proxy for fetal nutrition) and adult chronic conditions (Paneth \& Susser, 1995; Jones \& Swerdlow, 1996; Joseph \& Kramer, 1996) it is unlikely that significant qualitative developments in this area of research will be provided by additional observational studies, unless they were carried out to exploit specific opportunities provided by a unique nutritional setting. These should allow for a separate estimate of the timing and degree of fetal nutrition in addition to birth weight itself. While these circumstances are likely to be rare they should be utilized whenever possible.

However, more systematic attempts should be made to test well-defined hypotheses in which early nutrition is linked with adult health outcomes; this has already been suggested by others (Paneth \& Susser, 1995; Paneth et al. 1996). From the Dutch famine birth cohort findings it appears that the intra-uterine period of famine is the critical factor with regard to reproductive health outcomes. There are, however, many other perinatal measures for which an association with diseases in adult life has been postulated. These include maternal prepregnancy weight or height, maternal weight gain, birth weight, birth length, ponderal index (birth weight/length ${ }^{3}$ ) head circumference at birth, placental weight, placental ratio (placental weight:birth weight) and weight in infancy (Barker, 1992). Clearly the time has come when specific hypotheses should be formulated and specified before the analysis of additional studies, in order to facilitate the scrutiny of such hypotheses with empirical data.

Further qualitative developments can also be expected from the follow-up of subjects enrolled in past nutritionintervention trials. Among several others, these include the randomized controlled trial of prenatal nutritional supplementation in New York City (Rush et al. 1980). The study subjects are currently about 20 years old and may be difficult to locate. Because of the potential importance of a successful follow-up the possibility should nevertheless be explored in a feasibility study.

Last, further qualitative developments should be attempted by the systematic experimental study of perinatal nutrition and adult health in laboratory animals. Whereas some past experiments were directly inspired by findings from the Dutch famine (Jones \& Friedman, 1982, 1983; Enns et al. 1983), further efforts should be undertaken to increase our understanding of the biology of the long-term health effects. This can only be done by the integration of the findings of observational and experimental studies in human subjects and in animals.

\section{Acknowledgements}

This study was supported in part by the Milupa Aktiengesellschaft, Friedricksdorf, Germany, by contract 532K06-5-10, United States Department of Agriculture, and by grant 1R01-HD-26492-01/02, United States National Institutes of Health. Professors P.E. Treffers and J.G. Koppe, Academic Medical Center, University of Amster- 
dam, provided support and access to the hospital records from 1944-6. The hospital medical archives department and the Gemeentearchief and Bevolkingsregister of Amsterdam and other cities in The Netherlands assisted in patient location and follow-up. Professors Z. A. Stein and M. W. Susser provided advice and support throughout the study period and the contributions of my collaborators $A$. D. Stein and A. C. J. Ravelli are gratefully acknowledged.

\section{References}

Bakketeig LS, Hoffman HJ \& Harley EE (1979) The tendency to repeat gestational age and birth weight in successive births. American Joumal of Obstetrics and Gynecology 135, 10861103.

Barker DJP (editor) (1992) Fetal and Infant Origins of Adult Disease. London: British Medical Journal Publishing Group.

Barker DJP (1994) Mothers, Babies, and Diseases in Later Life. London: British Medical Journal Publishing Group.

Barker DJP (1995) Fetal origins of coronary heart disease. British Medical Journal 311, 171-174.

Billewicz WS \& Thomson AM (1973) Birthweights in consecutive pregnancies. Journal of Obstetrics and Gynaecology of the British Commonwealth 80, 491-498.

Burger GCE, Drummond JC \& Sandstead HR (1948) Malnutrition and Starvation in Western Netherlands, September 1944 to July 1945, Parts I and II. 's-Gravenhage, The Netherlands: Staatsuitgeverij.

De Jong L (1981) Het Koninkrijk der Nederlanden in de tweede Wereldoorlog 1939-1945 (The Kingdom of The Netherlands during the Second World War 1939-1945), Deel 10b. 'sGravenhage, The Netherlands; Staatsuitgeverij.

Emanue] I, Filakti H, Alberman E \& Evans SJ (1992) Intergenerational studies on human birthweight from the 1958 birth cohort. II. Do parents who were twins have babies as heavy as those born to singletons? British Joumal of Obstetrics and Gynecology 99, 836-840.

Enns MP, Wilson MW, Grinker JA \& Faust IM (1983) Prenatal food restriction and subsequent weight gain in male rats. Science 219, 1094.

Jones AP \& Friedman MI (1982) Obesity and adipocyte abnormalities in offspring of rats undernourished during pregnancy. Science 215, 1518-1519.

Jones AP \& Friedman MI (1983) Reply to Enns et al. Science 219, 1094.

Jones ME \& Swerdlow AJ (1996) Bias caused by migration in case-control studies of prenatal risk factors for childhood and adult diseases. American Journal of Epidemiology 143, 823831.

Joseph KS \& Kramer MS (1996) Review of the evidence on fetal and early childhood antecedents of adult chronic disease. Epidemiologic Reviews 18, 158-174.

Karn MN, Lang-Brown H, MacKenzie H \& Penrose LS (1951) Birth weight, gestation time and survival in sibs. Annals of Eugenics (London) 15, 306-322.

Kloosterman GJ (1970) On intrauterine growth. The significance of prenatal care. International Journal of Gynaecology and Obstetrics 8, 895-912.

Kramer MS \& Joseph KS (1996) Enigma of fetal/infant-origins hypothesis. Lancet 348, 1254-1255.

Lister D \& McCance RA (1965) The effect of two diets on the growth, reproduction and ultimate size of guinea-pigs. British Journal of Nutrition 19, 311-319.
Lumey LH (1988) Obstetric performance of women after in utero exposure to the Dutch famine. PhD Thesis, Graduate School of Arts and Sciences, Columbia University, New York.

Lumey LH (1992) Decreased birth weights in infants after maternal in utero exposure to the Dutch famine. Paediatric and Perinatal Epidemiology 7, 354-367.

Lumey LH (1993) Maternal nutrition, fetal health and morbidity in adulthood: lessons from the Dutch hunger winter. In Care, Concern and Cure in Perinatal Medicine. Proceedings XIII European Congress of Perinatal Medicine, pp. 313-320 [JG Koppe, TKAB Eskes, HP van Geijn, PE Wiesenhaan and JH Ruys, editors]. New York: Parthenon Publishing Group.

Lumey LH (1996) The Dutch famine of 1944-1945: Short term and long term consequences. In Santé et Mortalité des Enfants en Europe. Child Health and Mortality in Europe. Chaire Quetelet 1994, pp. 299-310 [G Masuy-Stroobant, C Gourbin and $\mathrm{P}$ Buekens, editors]. Louvain-la-Neuve: Academia-Bruylant L'Harmattan.

Lumey LH (1998) Compensatory placental growth after restricted maternal nutrition in early pregnancy. Placenta 19 , $105-111$.

Lumey LH, Ravelli ACJ, Wiessing LG, Koppe JG, Treffers PE \& Stein ZA (1993) The Dutch famine birth cohort study: Design, validation of exposure, and selected characteristics of subjects after 43 years follow-up. Paediatric and Perinatal Epidemiology 7, 354-367.

Lumey LH \& Stein AD (1997) Offspring birth weights after maternal intrauterine undernutrition: a comparison within sibships. American Journal of Epidemiology 146, 810 819.

Lumey LH \& Stein AD (1998) In utero exposure to famine and subsequent fertility: The Dutch famine birth cohort study. American Journal of Public Health (In the Press).

Lumey LH, Stein AD \& Ravelli ACJ (1994) Maternal recall of birth weights of adult children: Validation by hospital and well baby clinic records. International Journal of Epidemiology 23, 1006-1012.

Lumey LH, Stein AD \& Ravelli ACJ (1995a) Timing of prenatal starvation in women and birth weight in their first and second born offspring: the Dutch famine birth cohort study. European Journal of Obstetrics and Gynecology and Reproductive Biology 61, 23-30.

Lumey LH, Stein AD \& Ravelli ACJ (1995b) Timing of prenatal starvation and offspring birth weight: an update. European Journal of Obstetrics and Gynecology and Reproductive Biology 63, 197.

Lumey LH \& Van Poppel FWA (1994) The Dutch famine of 1944-45: Mortality and morbidity in past and present generations. Social History and Medicine 7, 229-246.

Magnus P, Berg K \& Bjerkedal T (1985) No significant difference in birth weight for offspring of birth weight discordant monozygotic female twins. Early Human Development 12, 55-59.

McCance RA \& Widdowson EM (1974) The determinants of growth and form. Proceedings of the Royal Society of London B 185, 1-7.

Paneth N, Ahmed F \& Stein AD (1996) Early nutritional origins of hypertension: a hypothesis still lacking support. Journal of Hypertension 14, Suppl., S121-S129.

Paneth N \& Susser M (1995) Early origin of coronary heart disease (the 'Barker hypothesis'). British Medical Journal 310, 411-412.

Ravelli ACJ, Stam GA, Stein ZA \& Lumey LH (1992) Birthweight, adult weight and offspring birthweight after inutero exposure to the Dutch famine of 1944-1945. Abstracts XIIIth European Congress of Perinatal Medicine. Journal of Perinatal Medicine 20, Suppl. 1, 205. 
Ravelli GP, Stein ZA \& Susser MW (1976) Obesity in young men after famine exposure in utero and early infancy. New England Journal of Medicine 295, 349-353.

Rush D, Stein Z \& Susser M (1980) A randomized controlled trial of prenatal nutritional supplementation in New York City. Paediatrics 65, 683-697.

Sindram IS (1953) De invloed van ondervoeding op de groei van de vrucht (The effect of undernutrition on fetal growth). Nederlands Tijdschrift voor Verloskunde en Gynaecologie 53, 30-48.

Smith CA (1947) The effect of wartime starvation in Holland upon pregnancy and its product. American Journal of Obstetrics and Gynecology 53, 599-608.

Stein AD \& Lumey LH (1996) The association of maternal and offspring birth weights under conditions affecting maternal birth weight: the Dutch famine birth cohort study. American Journal of Epidemiology 143, S54 Abstr.

Stein AD, Ravelli ACJ \& Lumey LH (1995) Famine, thirdtrimester pregnancy weight gain, and intrauterine growth: the Dutch famine birth cohort study. Human Biology 67, 135-150.

Stein ZA, Susser M, Saenger G \& Marolla F (1975) Famine and Human Development: The Dutch Hunger Winter of 1944-1945. New York: Oxford University Press.

Stewart RJC, Preece RF \& Sheppard HG (1975) Twelve generations of marginal protein deficiency. British Journal of Nutrition 33, 233-253.
Susser MW \& Stein Z (1994) Timing in prenatal nutrition: a reprise of the Dutch famine study. Nutrition Reviews 52, 84-94.

Thomson AM, Billewicz WZ \& Hytten FE (1968) The assessment of fetal growth. Journal of Obstetrics and Gynaecology of the British Commonwealth 73, 903-916.

Trienekens GMT (1985) Tussen ons volk en de honger. De voedselvoorziening 1940-1945 (Between our People and Starvation. Government Food Rations between 1940-1945). Utrecht, The Netherlands: Matrijs.

Weiss W \& Jackson EC (1969) Maternal factors affecting birth weight. In Perinatal Factors Affecting Human Development, pp. 54-59 [W Weiss and EC Jackson, editors]. Washington, DC: Pan American Health Organization.

Widdowson EM (1971) Prenatal growth retardation in the pig. I. Organ size and cellular development at birth and after growth to maturity. Biology of the Neonate 19, 329-340.

Winick M \& Noble A (1965) Quantitative changes in DNA, RNA and protein during prenatal and postnatal growth in the rat. Developmental Biology 12, 451-466.

Winick M \& Noble A (1966) Cellular response in rats during malnutrition at various ages. Journal of Nutrition $\mathbf{8 9}$, 300-306.

Zamenhof S \& van Marthens E (1982) Chronic undernutrition for 10 generations: differential effects on brain and body development among neonatal rats. Nutrition Reports International 26, 703-709. 